\title{
Effects of Controling of Post Operative Hypergycemia (Stress Induced Hyperglycemia) in Adult Non-Diabetic Patients Undergoing Mitral Valve Replacement Surgery Under Cardiopulmonary Bypass
}

\author{
Md. Armane Wadud ${ }^{1}$, Syed Tanvir Ahmed², Shahnoor Aziz ${ }^{3}$, Ibrahim Khalilullah ${ }^{4}$, C M Shaheen Kabir ${ }^{5}$
}

\begin{abstract}
:
Objectives: The objective of this study was to see whether there is an association between high blood glucose levels after operation under CPB and post operative morbidity and mortality.

Methodology: This cohort study was carried out in the Department of Cardiac Surgery at National Institute of Cardiovascular DiseaseS (NICVD), Sher-e-Bangla Nagar, Dhaka from January, 2012 to December, 2013 for a period of twenty four (24) months. A total number of 110 patients who underwent MVR operation with CPB were enrolled in this study as per inclusion and exclusion criteria. Patients were divided into two groups according to their post operative blood glucose levels, recorded with in first $60 \mathrm{hrs}$ after mitral valve replacement surgery under cardiopulmonay bypass. Patients having blood glucose level of less than $10.1 \mathrm{mmol} / \mathrm{L}$ (unexposed) and patients having blood lactate level of $10.1 \mathrm{mmol} / \mathrm{L}$ or more (exposed) were grouped. Post operative variables were observed and recorded during the hospital course of the patient.
\end{abstract}

Result: A total number of 110 patients were enrolled in this study. Blood glucose levels lower than or equal to10 $\mathrm{mmol} / \mathrm{L}$ after MVR were present in 55(50\%) patients (Group A) Blood glucose levels higher than $10 \mathrm{mmol} / \mathrm{L}$ after MVR were present in $55(50 \%)$ patients. Postoperative morbidity was higher in this group (Group $B$ ) than in the patients who had peak blood glucose levels of less than or equal to $10 \mathrm{mmol} / \mathrm{L}$ MVR (p 0.001). Postoperative ICU stay was prolonged in patients with elevated levels of blood glucose after MVR under CPB compared with of patients with lower blood glucose levels ( $p$ 0.001). Other common morbidities are neurological complication ( $p$ 0.04), renal dysfunction ( $p$ 0.01 ), wound infection ( $\mathrm{p} 0.04$ ), post-operative hospital stay ( $p 0.004)$. also higher in group B patient, as well as mortality.

Conclusions: Blood glucose concentration of $10.1 \mathrm{mmol} /$ $L$ or higher after MVR under CPB is an important issues related to postoperative morbidity and mortality.

Key words: Non diabetic patient, mitral valve replacement. post operative blood glucose control.

(Bangladesh Heart Journal 2019; 34(1): 44-51)

Introduction:

Over the last decade, the incidence of diabetes mellitus has increased markedly both in developed and developing

countries ${ }^{1}$ Diabetes mellitus has been associated with a poor clinical outcome after cardiac surgery, including a

1. Assistant Professor of Cardiac Surgery, Ibrahim Cardiac Hospital \& Research Institute, Shahbag, Dhaka-1000, Bangladesh

2. Assistant Professor of Cardiac Surgery, Ibrahim Cardiac Hospital \& Research Institute, Shahbag, Dhaka-1000, Bangladesh

3. Resitrar of Cardiac Surgery, Ibrahim Cardiac Hospital \& Research Institute, Shahbag, Dhaka-1000, Bangladesh.

4. Registrar of Cardiac Anaesthesia, Ibrahim Cardiac Hospital \& Research Institute, Shahbag, Dhaka-1000, Bangladesh

5. Associate Professor \& Consultant of Cardiology, Ibrahim Cardiac Hospital \& Research Institute, Shahbag, Dhaka-1000, Bangladesh Address of Correspondence: Dr. Md. Armane Wadud, MS, MRCS, Assistant Professor of Cardiac Surgery, Ibrahim Cardiac Hospital \& Research Institute, Shahbag, Dhaka-1000, Bangladesh, e-mail:armanewadud2@yahoo.com, cell:01673147547

DOI: https://doi.org/10.3329/bhj.v34i1.41907

Copyright (C) 2017 Bangladesh Cardiac Society. Published by Bangladesh Cardiac Society. This is an Open Access articles published under the Creative Commons Attribution-NonCommercial 4.0 International License (CC BY-NC). This license permits use, distribution and reproduction in any medium, provided the original work is properly cited and is not used for commercial purposes. 
higher incidence of wound infections, ischemic events, neurological and renal complications, and mortality 2 . Nevertheless, derangement of glucose metabolism after surgery is not specific to patients with $\mathrm{DM}^{3}$.

Hyperglycemia is present in up to $80 \%$ of patients after cardiac surgery, about $80 \%$ of ICU patients with hyperglycemia have no history of diabetes prior to admission. The risk of hospital complications relates to the severity of hyperglycemia, with a higher risk observed in patients without a history of diabetes compared to those with known diabetes. Improvement in glycemic control reduces hospital complications and mortality. A target glucose level between 7.8 and $10.0 \mathrm{mmol} / \mathrm{l}$ (140 and 180 $\mathrm{mg} / \mathrm{dl}$ ) is recommended for the majority of ICU patients ${ }^{4}$.

Hyperglycemia is a marker of in-hospital morbidity and mortality ${ }^{5}$. Observational studies showed that hyperglycemia predicted mortality and infections after surgery ${ }^{6}$. Intravenous insulin regimens to reduce blood glucose immediately after surgery decreased the incidence of infection ${ }^{7}$. Intensive insulin therapy markedly decreased septicemia and mortality among critically ill patients in a surgical ICU ${ }^{8}$.

In recent years, it has also been recognized that tight glucose control markedly improves acute outcomes of hospitalized diabetic patients, including lowering the risk of infection and death. Reports have demonstrated that tight glucose control with continuous intravenous insulin in diabetic cardiac surgery patients reduces mediastinitis, mortality, costs, and length of stay ${ }^{9}$. Lazar and colleagues showed there was also a reduction in postoperative atrial fibrillation and ischemia in cardiac surgery patients. There are now reports demonstrating the outcome benefits of tight glucose control in hospitalized patients, even in the absence of diabetes ${ }^{10}$. For this reason, many researchers have proposed tight glucose control as an effective tool to prevent the deleterious effects of glucose unbalance ${ }^{11}$.

The disturbances in blood glucose homeostasis have been attributed to insulin resistance and/or a failure of pancreatic â-cell function caused by the systemic inflammatory response syndrome after cardiopulmonary bypass (CPB) and its effects on systemic temperature ${ }^{12}$ Hyperglycemia is associated with poor outcomes in critically ill and post surgical patients ${ }^{3}$.

Acute hyperglycemia may also have its own deleterious effects that can lead to poor peri-operative outcomes. Once the renal threshold is crossed osmotic diuresis leads to dehydration, electrolyte and acid base imbalance. Hyperosmolarity leads to central nervous system dysfunction and its rapid correction can worsen cerebral oedema ${ }^{13}$.

Acute hyperglycemia occurring intra-operatively abolishes ischemic preconditioning and amplifies reperfusion injury to the heart. In addition, during ischemia, glucose is the preferred substrate for the myocardium, but marked insulin resistance leads to hyperglycemia as a result of impaired cell uptake of glucose which in turn leads to increased concentrations of free fatty acids. Fatty acids are detrimental to the ischemic myocardium because of the increased oxygen consumption required to metabolize the new substrate. Hyperglycemia also leads to increased free radical release and hence increased oxidative stress, causing endothelial dysfunction, which may further affect myocardial ischemia ${ }^{1}$.

Hyperglycemia has a pro-inflammatory action that is normally restrained by the anti-inflammatory effect of insulin secreted in response to that stimulus. Free fatty acids (FFAs) also induce pro-inflammatory changes. During illness, stress increases the concentration of counterregulatory hormones (mainly glucagon, an epinephrine). Given this background, it is plausible that in the presence of high concentrations of both glucose and FFA, inflammation is more prominent. High circulating concentrations of glucose and FFAs may explain, at least in part, the oxidative and inflammatory derangements during acute illness; insulin may exert its anti-inflammatory action by ameliorating glucose and lipid parameters ${ }^{14}$.

Cardiopulmonary bypass increases post-operative glycemia and insulin consumption in both diabetic and non-diabetic patients. The use of cardiopulmonary bypass during cardiac surgery diabetic patients is associated with more difficult glycemic control in early post operative period ${ }^{15}$.

\section{Material \& Method:}

This Prospective, Observational studystudy was conducted in the department of cardiovascular surgery, National Institute of Cardiovascular Diseases (NICVD).Sher-e-Bangla Nagar, Dhaka from January 2012 to December 2013. The study was approved by Ethical review committee of NICVD. Informed written consent was obtained from each patient and data will be collected in approved data collection form. The participants had the right to withdraw himself or herself from the study at anytime during study. Interest of study was given highest priority and confidentiality was maintained with safe guard of the right and health of the participants.

\section{Inclusion Criteria:}

All non-diabetic adult patients undergoing mitral valve replacement surgery with the use of cardiopulmonary bypass both who are either normoglycemic or developed hyperglycemia postoperatively.

\section{Exclusion Criteria:}

Age: Below 18 yrs, above 65years, all diabetic patients, emergency cardiac surgery, patients with poor LV 
function. (LVEF $<30 \%$ ), patients with redo-valve surgery, patient with LA thrombus, patient with congestive cardiac failure, patients with cardiomyopathy, patient with renal failure, patients with stroke, Patients with prolonged cardiopulmonary bypass(>120 mins).

Study population: The study was carried out on nondiabetic adult patients undergoing mitral valve replacement surgery with the use of cardiopulmonary bypass developing postoperative hyperglycemia fulfilling the inclusion and exclusion criteria.

Preoperative characteristics of study patient: Each patient was assessed by history, clinical examination, and pre operative investigations (All routine investigation and was recorded in the preformed data.

Grouping of the Patients.

Group: A ( $n=55)$ Patients with good post operative blood glucose control(10 $\mathrm{mmol} / \mathrm{l}$ or less).

Group: B ( $n=55)$ Patients with poor post operative blood glucose control( blood glucose $>10 \mathrm{mmol} / \mathrm{l}$ ).

\section{Anesthesia, surgical technique and postoperative management}

Standard anesthetic and surgical techniques was followed, heparin was given to maintain the activated clotting time at 480 seconds throughout CPB. A standard CPB circuit was used with non pulsatile flow at a rate through out bypass of $2.4 \mathrm{~L} / \mathrm{min} / \mathrm{m} 2$ and a mean arterial pressure kept 50 to $60 \mathrm{~mm} \mathrm{Hg}$. Myocardial protection was achieved with intermittent ante grade cold-blood cardioplegia. For all cases, myocardial protection was predominantly maintained by intermittent antegrade with moderate systemic hypothermia $\left(28^{\circ} \mathrm{C}\right.$ to $\left.32^{\circ} \mathrm{C}\right)$.

For all patients mechanical bi-leaflet valve prosthesis was used. At the end of mitral valve replacement, adequate de-airation was ensured, patients were weaned from CPB, then patients was transferred to the intensive care unit and ventilated with $70 \%$ oxygen using volume-controlled ventilation. Patients were extubated after fulfilling the criteria for extubation. Proper perioperative analgesia and sedation was ensured. Patient was discharged from ICU after attainment of haemodynamic stability, weaning from all inotropic support and removal of chest drain.

Per-operatively CPB time, X-clamp time, post operatively highest post operative (venous) blood glucose value ( within first $60 \mathrm{hrs}$ ), mechanical ventilation time( hrs), ICU stay (hrs), neurological complications (stroke), renal failure (elevated serum creatinine two times preoperative value), post surgical infection (wound infection)and inhospital mortality were recorded and were compared between two groups. Proper management of all these complications were be done accordingly. After achieving target INR patients were discharged. Patients developing complications were kept in hospital for adequate management.

\section{Post-operative Glucose Measurement:}

Venous sample of blood will be taken to measure blood glucose. Blood glucose measurement was done by enzymatic colourimetric method with DIMENSION XPAND, PLUS, SIEMENS analyzer.

\section{Post-operative Glucose Management:}

All MVR patients developing post operative hyperglycemia (blood glucose $>10 \mathrm{mmol} / \mathrm{L}$ ) were started on a slidingscale insulin infusion as well as iv bolus soon after surgery to maintain blood glucose levels less than $10 \mathrm{mmol} / \mathrm{L}$ according to a standard protocol. Multiple samples were collected according to the protocol for blood glucose measurement. The highest blood glucose value was recorded within $60 \mathrm{hrs}$ after surgery.

Protocol for blood glucose management: ( Bojar $5^{\text {th }}$ edition P 755)

\begin{tabular}{|c|c|c|}
\hline Blood Sugar & Regular Insulin IV Bolus & Infusion Rate \\
\hline $\begin{array}{l}151-200 \\
8.3-11.11 \mathrm{mmol} / \mathrm{l}\end{array}$ & No bolus & 2Units/h \\
\hline $\begin{array}{l}201-240 \\
11.12-13.33 \mathrm{mmol} / /\end{array}$ & 4 Units & 2 Units/h \\
\hline $\begin{array}{l}241-280 \\
13.34-15.55 \mathrm{mmol} / \mathrm{l}\end{array}$ & 6 Units & 4 Units/h \\
\hline $\begin{array}{l}281-320 \\
15.56-17.77 \mathrm{mmol} / \mathrm{l}\end{array}$ & 10 Units & 6 Units/h \\
\hline
\end{tabular}

This infusion was continued for the first 24 hours and blood glucose measurement was done hourly. Then, patients were switched to subcutaneous soluble insulin, and blood sugar levels were monitored every 8 hours.

Data Collection: Data were collected by interview of the patients, clinical examination, laboratory investigation, hospital records peroperative and postoperative findings . Then data was put in data master sheet using SPSS.

\section{Statistical Analysis:}

After processing all available data, statistical significance was analyzed. Data were expressed as mean $\pm S D$, frequency, percentage as applicable. Intergroup comparisons of BGC after surgery was done using 2tailed $t$ tests to determine the significance of difference. To show the relationship between the variables Pearson correlation analysis was performed. P-value $<0.05$ will be considered statistically significant. All the data entry and analysis were done by using SPSS (latest version) soft ware program. 
Results:

A total number of 110 elective MVR patients were enrolled for this study and divided into two groups according to the post operative blood glucose level. Those patients who were below $\leq 10 \mathrm{mmol} / \mathrm{L}$ were designated as Group $A$ and those patients who were above $10 \mathrm{mmol} / \mathrm{L}$ were designated as Group B.

Table-I

Age distribution of the study patients $(n=110)$

\begin{tabular}{|c|c|c|c|c|c|c|c|}
\hline \multirow[t]{2}{*}{ Age in years } & \multicolumn{2}{|c|}{ Group A $(n=55)$} & \multicolumn{2}{|c|}{ Group B (n=55 ) } & \multicolumn{2}{|c|}{ Total $(n=110)$} & \multirow[t]{2}{*}{$p$ value } \\
\hline & Number & $\%$ & Number & $\%$ & Number & $\%$ & \\
\hline $20-30$ & 12 & 21.8 & 14 & 25.5 & 26 & 23.6 & \\
\hline $31-40$ & 31 & 56.4 & 31 & 56.4 & 62 & 56.4 & \\
\hline $41-50$ & 12 & 21.8 & 10 & 18.2 & 22 & 20.0 & \\
\hline Mean \pm SD(Range) & \multicolumn{2}{|c|}{$36.4 \pm 6.7(20-50)$} & \multicolumn{2}{|c|}{$35.3 \pm 6.2(22-50)$} & \multicolumn{2}{|c|}{$35.9 \pm 6.5(20-50)$} & $0.34^{\mathrm{ns}}$ \\
\hline
\end{tabular}

Table-II

Distribution of study patients according to sex $(n=110)$

\begin{tabular}{lcccc}
\hline Sex & Study group & Total & P value \\
\hline \multirow{2}{*}{ Male } & Group A(n=55) & Group B $(\mathrm{n}=55)$ & & \\
Female & $25(45.5 \%)$ & $26(47.3 \%)$ & $51(46.4 \%)$ & $0.84^{\mathrm{ns}}$ \\
\hline Total & $30(54.5 \%)$ & $29(52.7 \%)$ & $59(53.6 \%)$ & \\
\hline
\end{tabular}

Table-III

Distribution of BMI and BSA status of the study patients $(n=110)$

\begin{tabular}{lccc}
\hline Categories & \multicolumn{2}{c}{ Study group } & $p$ value \\
\hline & Group $\mathrm{A}(\mathrm{n}=55)$ mean \pm SD & Group $\mathrm{B}(\mathrm{n}=55)$ mean $\pm \mathrm{SD}$ & $0.82^{\mathrm{ns}}$ \\
$\mathrm{BMI}\left(\mathrm{kg} / \mathrm{m}^{2}\right)$ & $21.4 \pm 1.7$ & $21.5 \pm 1.4$ & $0.91^{\mathrm{ns}}$ \\
BSA $\left(\mathrm{m}^{2}\right)$ & $0.7 \pm 0.1$ & $0.7 \pm 0.1$ & \\
\hline
\end{tabular}

Table-IV

Distribution of pre-operative biochemical parameters among the study patients $(n=110)$

\begin{tabular}{|c|c|c|c|}
\hline \multirow[t]{2}{*}{ Variables } & \multicolumn{2}{|c|}{ Glucose Group } & \multirow[t]{2}{*}{$p$ value } \\
\hline & Group $A(n=55)$ mean $\pm S D$ & Group $B(n=55)$ mean $\pm S D$ & \\
\hline $\mathrm{HbA}_{1} \mathrm{C}(\%)$ & $5.22 \pm 0.35$ & $5.22 \pm 0.38$ & $0.98^{\mathrm{ns}}$ \\
\hline S. Creatinine (mg/dl) & $0.78 \pm 0.08$ & $0.81 \pm 0.07$ & $0.10^{\text {ns }}$ \\
\hline RBS (mmol/L) & $6.24 \pm 0.59$ & $6.36 \pm 0.57$ & $0.30^{\text {ns }}$ \\
\hline
\end{tabular}

Table-V

Echocardiographic results ( LVEF) among the study patients $(n=110)$

\begin{tabular}{lccc}
\hline Variable & \multicolumn{2}{c}{ Study group } & $p$ value \\
\cline { 2 - 4 } & Group A(n=55)mean \pm SD & Group B(n=55)mean $\pm S D$ & \\
\hline LV EF \% & $52.29 \pm 5.01$ & $52.36 \pm 4.46$ & $0.93^{\text {ns }}$ \\
\hline
\end{tabular}


Table-VI

Comparison of per-operative variables between groups

\begin{tabular}{lccc}
\hline Duration & \multicolumn{2}{c}{ Study group } & $p$ value \\
\cline { 2 - 4 } & $\begin{array}{c}\text { Group } A(n=55) \\
\text { Mean } \pm \text { SD }\end{array}$ & Group B $(n=55)$ & Mean $\pm S D$ \\
\hline CPB time (min.) & $85.07 \pm 8.46$ & $88.65 \pm 14.42$ & $0.04^{\mathrm{s}}$ \\
X clamp time (min.) & $57.21 \pm 6.03$ & $60.05 \pm 6.66$ & $0.02^{\mathrm{s}}$ \\
\hline
\end{tabular}

Table-VII

Distribution stress induced hyperglycemia among the post surgical patients $(n=110)$.

\begin{tabular}{lccc}
\hline Stress induced hyperglycemia & \multicolumn{2}{c}{ Post operative Blood Glucose } & Total \\
\cline { 2 - 3 } & $\begin{array}{c}\text { Hyperglycemic }>7.80 \mathrm{mmol} / \mathrm{L} \\
(\mathrm{n}=82)\end{array}$ & $\begin{array}{c}\text { Normoglycemic } \leq 7.80 \mathrm{mmol} / \mathrm{L} \\
(\mathrm{n}=28)\end{array}$ & $110(100.0)$ \\
\hline & $84(76.4)$ & $26(23.6)$ & \\
\hline
\end{tabular}

Table-VIII

Comparison of highest post operative blood glucose value among the study patients $(n=110)$

\begin{tabular}{lccc}
\hline Highest post operative blood & \multicolumn{2}{c}{ Study Group } & p value \\
\cline { 2 - 3 } glucose value & Group $A(n=55)$ & Group $B(n=55)$ & $0.001^{s}$ \\
Mean $\pm S D m m o l / L$ & $9.12 \pm 1.42$ & $14.18 \pm 2.24$ & \\
\hline
\end{tabular}

Table-IX

Comparison of Mechanical Ventilation Time (MVT) and Duration of ICU stay among the study population ( $n=110)$

\begin{tabular}{llcc}
\hline Variables & \multicolumn{2}{c}{ Study group } & $p$ value \\
\cline { 2 - 4 } & $\begin{array}{c}\text { Group A(n=55) } \\
\text { Mean } \pm \text { SD }\end{array}$ & $\begin{array}{c}\text { Group B(n=55) } \\
\text { Mean } \pm S D\end{array}$ & $0.02^{\mathrm{s}}$ \\
\hline Mechanical Ventilation Time (min.) & $8.94 \pm 2.47$ & $13.02 \pm 10.42$ & $0.001^{\mathrm{s}}$ \\
Duration of ICU stay in days & $1.47 \pm 0.50$ & $2.00 \pm 0.66$ & \\
\hline
\end{tabular}

Table-X

Comparison of post operative complications among the study patients $(n=110)$

\begin{tabular}{|c|c|c|c|c|c|}
\hline \multirow[t]{3}{*}{ Variables } & \multicolumn{4}{|c|}{ Study group } & \multirow[t]{3}{*}{$p$ value } \\
\hline & \multicolumn{2}{|c|}{ Group $A(n=55)$} & \multicolumn{2}{|c|}{ Group $B(n=55)$} & \\
\hline & No. & $\%$ & No. & $\%$ & \\
\hline Neurological Complications (Present) & 3 & 5.5 & 11 & 20.0 & $0.04^{\mathrm{s}}$ \\
\hline \multirow[t]{2}{*}{ Renal Dysfunction (Present) } & 3 & 5.5 & 13 & 23.3 & $0.01^{\mathrm{s}}$ \\
\hline & \multicolumn{2}{|c|}{ Mean $\pm S D$} & \multicolumn{2}{|c|}{ Mean $\pm S D$} & \\
\hline \multirow[t]{2}{*}{ Post operative Hospital stay in days } & \multicolumn{2}{|c|}{$8.89 \pm 1.81$} & \multicolumn{2}{|c|}{$10.38 \pm 3.28$} & $0.004^{s}$ \\
\hline & No. & $\%$ & No. & $\%$ & \\
\hline Post surgical infection(Present) & 4 & 7.3 & 12 & 21.8 & $0.04^{\mathrm{s}}$ \\
\hline Mortality (Yes) & 1 & 1.8 & 3 & 5.5 & $0.31^{\text {ns }}$ \\
\hline
\end{tabular}


Table-XI

Distribution of adverse in-hospital outcome among the study patients $(n=110)$

\begin{tabular}{lcccccc}
\hline Adverse outcome & \multicolumn{2}{c}{ Study group } & \multicolumn{2}{c}{ p value } \\
\cline { 2 - 3 } & \multicolumn{2}{c}{ Group A(n=55) } & & & \\
\cline { 2 - 4 } \cline { 5 - 6 } & No. & & & Go. & & \\
\hline Present & 5 & 9.1 & & 23 & 41.8 & $0.001^{\text {s }}$ \\
Absent & 50 & 90.9 & & 32 & 58.2 & \\
\hline
\end{tabular}

Table-XII

Comparison of highest post operative blood glucose value among the study patients according to hospital outcome $(n=110)$

\begin{tabular}{lccc}
\hline Highest post operative blood glucose value & \multicolumn{2}{c}{ Hospital outcome } & p value \\
\cline { 2 - 3 } & Adverse $(\mathrm{n}=28)$ & $\operatorname{Good}(\mathrm{n}=82)$ & \\
\hline & & & $0.001^{\mathrm{s}}$ \\
Mean $\pm \mathrm{SDmmol} / \mathrm{L}$ & $15.18 \pm 3.05$ & $10.44 \pm 2.12$ & \\
\hline
\end{tabular}

\section{Discussion:}

The present study performed in NICVD, Dhaka, included a total number of 110 mitral valve replacement surgery patient under CPB and was divided into two groups according to post operative blood glucose level. Those patients whose highest blood sugar level were below or equal to $10 \mathrm{mmol} / \mathrm{L}$ were designated as group $A$ and those patients whose highest blood sugar level were above $10 \mathrm{mmol} / \mathrm{L}$ were designated as group $\mathrm{B}$. The distribution of study population is recorded according to age. All patients in group A 55(50.0\%) and group B $55(50.0 \%)$ are within less than 60 years group. It has been found that middle aged people or young adult persons most commonly underwent mitral valve replacement surgery in this study. ${ }^{16 .}$

The mean age of the studied patients were $35.9 \pm 6.5$ years ranging from 20 to 50 years. The mean age was found $36.4 \pm 6.7$ years in group $A$ and $35.3 \pm 6.5$ years in group $B$. There was no significant difference of age distribution between two groups $(P>0.05)$ (tabe 1). In the study of Chowdhury et al ${ }^{16}$ mean age was 33.08 years. Our observation was similar to these studies.

There was no significant sex difference between two groups ( $P>$.05). Males were $45.5 \%$ in group $A$ and $47.3 \%$ in group $B$. On the other hand female were $54.5 .8 \%$ in group A and $52.7 \%$ in group B (table 2). Females were more with mitral valve disease in the study of Shrestha et al ${ }^{16}$. Our findings were similar to those studies.

The distribution of stress induce hyperglycemia among the study population $85(78.54 \%)$, (table- 7 ). This result is consistent with other studies. Farnoosh et al, ${ }^{4}$ showed in one study that $80 \%$ non diabetic patients develop stress induced hyperglycemia after cardiac surgery during their ICU stay in their early post operative days.

The distribution of BMI, BSA, HbA1C, LVEF, Serum Creatinine and RBS between Blood Glucose groups were recorded (Table 3-6). Most of the patients were non smokers. The left ventricular ejection fraction was observed in group A and group B (52.29 \pm 5.01 vs $52.36 \pm 4.46)$ with statistically insignificant difference $(p>0.05)$. Body mass index and body surface area were almost identically distributed in both groups insignificant difference $(p>0.05)$.

The biochemical parameters were similar in the both groups. $\mathrm{HbA} 1 \mathrm{C}$ was found in group $\mathrm{A}$ and group $\mathrm{B}$ $(5.22 \pm 0.35$ vs $5.22 \pm 0.38)$ with statistically insignificant difference. Serum creatinine was observed in group $A$ and group $B(0.78 \pm 0.08$ vs $0.81 \pm 0.07)$ with statistically insignificant difference. Random blood sugar was also observed in group A and group B (6.24 \pm 0.59 vs $6.36 \pm 0.57)$ with statistically insignificant difference.

Mechanical ventilation time was observed significantly greater in group $B$ than group $A(8.94 \pm 2.47 v s 13.02 \pm 10.42)$ minute with $p=0.02$ ( Table-9). It was also observed that duration of ICU stay was observed (1.47 $\pm 0.50 v s 2.00 \pm 0.66)$ days which was significantly higher in group $B(p=0.001)$, (Table-9). Similar result was published by Ascione, et al., 1 , Ouattara,et al. ${ }^{2}$.

Neurological complication (Table-10) was observed $20 \%$ in group $B$ and $5.5 \%$ in group A with statistically significant 
difference $(p=0.04)$. Capes and his associates showed poor prognosis for poor postoperative blood glucose controlled individuals ${ }^{18}$.

Renal dysfunction (Table-10) was also observed 23.3\% in group $B$ and $5.5 \%$ in group A with statistically significant difference $(p=0.01)$. Similar result was published by Ascicone et $\mathrm{al}^{1}$. They showed that in post operative poor blood glucose control patients the renal dysfunction is about $25 \%$. Which is almost same as our study results.

Post operative hospital stay was observed in group $B$ and group $A(10.38 \pm 3.28$ vs $8.89 \pm 1.81)$ days with significant difference $(p=0.004)$. Ascione and associates in 2008 observer increased hospital stay in post operative hyperglycemic population. This finding is consistent with our study.

Post operative surgical infection (Table-10) was observed significantly greater in group $B$ than group $A(21.8 \%$ vs 7.3\%) with $p=0.04 .3(5.5 \%) \quad$ Ascione, et al., 2008 also showed significant wound infection resulted in post operative poor blood glucose group. Dandona and his colleagues explained this in their study ${ }^{14}$.

Patient's post operative death $3(3$ (5.5\%) in group B and $1(1.8 \%$ ) in group $A$ (table-10) which was found statistically insignificant $(p=0.31)$. Capes et al., 18 and Ascione, et al. ${ }^{1}$ showed significant mortality in poor post operative blood glucose control group of patients.

Highest post operative blood glucose level was observed significantly higher in adverse hospital outcome patients than good hospital outcome patients $(15.18 \pm 3.05$ vs10.44 \pm 2.12$) \mathrm{mmol} / \mathrm{L}$ with $p=0.001$. Similar result was published by Ascione et al ${ }^{1}$. Dandona et al ${ }^{14}$. So, controlling of post operative blood glucose level is an important factor to reducing adverse in hospital outcome.

\section{Conclusion:}

In conclusion, the findings of this study permit to conclude that a peak blood glucose level of $10.1 \mathrm{mmol} /$ $L$ or higher during CPB is associated with an increased risk of perioperative morbidity. Most common morbidities are infection, neurological complication and renal dysfunction. Post operative ICU stay and hospital stay is also longer in higher blood glucose group. Although mortality is higher in the high blood glucose group of patients operated under CPB during mitral valve surgery difference between higher and lower blood glucose group is not significant. Although initially we thought that a high blood glucose level could be an independent predictor of in-hospital mortality, but the study showed insignificant result. It would be worth mentionable that a higher proportion of mortality is observed in the higher post operative blood glucose group, a further study with larger sample size could be done to see the consequence.

\section{Limitations:}

There are some limitations in this study. Some are mentioned below.It was a purposive non-random sampling method.The proposed post operative blood glucose control threshold value differed from the threshold value chosen by other authors for different clinical setup.

For further study, the following recommendations are proposed: Further large scale study should be carried out. Further studies should be carried out to determine level of blood glucose control during and after CPB time and interventions based on blood glucose values to improve survival in adult non-diabetic cardiac surgical patients.

\section{References:}

1. Ascione R, Roger CA, Rajakaruna $C$ and Angelini GD. Inadequate Blood Glucose Control Is Associated With In-Hospital Mortality and Morbidity in Diabetic and Nondiabetic Patients Undergoing Cardiac Surgery.Circulation, American Heart Association; 2008;118(2):113-123.

2. Ouattara A, Lecomte $P$, Le Manach $Y$, Landi M, Jacqueminet S, Platonov I, Bonnet N, Riou B and Coriat $\mathrm{P}$. Poor intraoperative blood glucose control is associated with a worsened hospital outcome after cardiac surgery in diabetic patients. Anesthesiology 2005;103:687- 694.

3. Doenst T, Wijeysundera D, Karkouti K, Zechner C, Maganti M, Rao V and Borger MA. Hyperglycemia during cardiopulmonary bypass is an independent risk factor for mortality in patients undergoing cardiac surgery. Journal of Thoracic \& Cardiovascular Surgery. 2005;130:1144.

4. Farnoosh F, Dawn S, Guillermo E. Umpierrez. Glycemic control in non-diabetic critically ill patients .Best Practice \& Research Clinical Endocrinology \& Metabolism. 2011;25:813-824.

5. Umpierrez GE, Isaacs SD, Bazargan N, You X, Thaler LM, Kitabchi AE. 2002 Hyperglycemia: an independent marker of in-hospital mortality in patients with undiagnosed diabetes. Journal Clinical Endocrinology Metabolism;87:978-982. 
6. Pomposelli J, Baxter J, Babineau T. Early postoperative glucose control predicts nosocomial infection rate in diabetic patients. J Parenter Enteral Nutr 1998;2:77-81.

7. Furnary AP, Zerr KJ, Grunkemeier GL, Starr A. Continuous intravenous insulin infusion reduces the incidence of deep sternal wound infection in diabetic patients after cardiac surgical procedures. Annals of Thoracic Surgery 1999;67:352- 62.

8. Leibowitz G, Raizman E, Brezis M, Glaser B, Raz I and Shapira O. Effects of Moderate Intensity Glycemic Control After Cardiac Surgery. Ann Thorac Surg 2010;90:1825-1832.

9. Justine M. C, Frank W. Sellke, Michelle Fey, Mathew J. Doyle, Judy A. Krempin I Ralph de la Torre and John R. Liddicoat. Implementing Tight Glucose Control After Coronary Artery Bypass Surgery. Annals of Thorac Surg 2005;80:902-909.

10. Lazar HL, Chipkin SR, Fitzgerald CA, Bao Y, Cabral $\mathrm{H}$, Apstein CS. Tight glycemic control in diabetic coronary artery bypass graft patients improves perioperative outcomes and decreases recurrent ischemic events. Circulation. 2004;109:1497-502.

11. Van den Berghe G, Wouters P, Weekers F, Verwaest C, Bruyninckx F, Schetz M, Vlasselaers D, Ferdinande P, Lauwers P and Bouillon R. Intensive insulin therapy in the critically ill patients. New England Journal of Medicine 2001;345:1359-1.

12. Anderson RE, Brismar K, Barr G, Ivert T. Effects of cardiopulmonary bypass on glucose homeostasis after coronary artery bypass surgery. European Journal of Cardiothorac Surgery. 2005;28:425-430.
13. Akhtar S, Barash PG and InzucchiSE. Scientific Principles and Clinical Implications of Perioperative Glucose Regulation and Control. AnesthesiaAnalgesia. 2010;110; 478-498.

14. Dandona P, Aljada A, Bandyopadhyay A.The potential therapeutic role of insulin in acute myocardial infarction in patients admitted to intensive care and in those with unspecified hyperglycemia. Diabetes Care. 2003;26:516-519

15. Preiser JC. Restoring normoglycaemia: not so harmless. Critical Care. 2008;12:116.

16. Chowdhury UK, Jayanth $\mathrm{KH}$, Chetan D, Patel DM, Seth S, Yadav R, Sing R, Subramaniam G, Malik B, Venugopal $\mathrm{P}$, ' Serial radionuclide angiographic assessment of left ventricular ejection fraction and egional wall motion aftermitral valve replacement in patients with rheumatic disease', Am Heart J, 2006;152: 1201-1207

17. Shrestha NR, Pilgrim T, Karki P, Bhandari R, Basnet S, Tiwari S, Dhakal SS, Urban P. Rheumatic heart disease revisited: patterns of valvular involvement from a consecutive cohort in eastern Nepal. Journal of Cardiothorac Vascular Medicine. 2012;13:755-759.

18. Capes SE, Hunt D, Malmberg K, Pathak P, Gerstein H.C. Stress Hyperglycemia and Prognosis of Stroke inNondiabetic and Diabetic Patients. Stroke, Journal of The American Heart Association. 2001;32:2426-2432.

19. Bojar RM. Hyperglycemia Protocol for Cardiac Surgery Patients, in: Manual of perioperative care in adult cardiac surgery. 5th ed, Wiley-Blackwell, Chichester, West Sussex, PO19 8SQ, UK; $2011 ; 738$. 